\title{
Nitric oxide synthase activity in rat gastric mucosa contributes to mucin syn- thesis elicited by calcitonin gene-related peptide
}

\author{
Takafumi Ichikawa ${ }^{1}$, Tatsumi Kusakabe ${ }^{2}$, Yukari Gono ${ }^{3}$, Nobuaki Shikama ${ }^{3}$, Hiromi Hiruma ${ }^{4}$, Tadashi \\ KAWAKAMI $^{4}$ and Kazuhiko IsHIHARA ${ }^{5}$ \\ Departments of ${ }^{1}$ Biochemistry, ${ }^{3}$ Internal Medicine, and ${ }^{4}$ Physiology, Kitasato University School of Medicine; ${ }^{5}$ Department of Biochem- \\ istry, Kitasato University School of Allied Health Sciences, Sagamihara 228-8555; and ${ }^{2}$ Department of Sport and Medical Science, \\ Kokushikan University, Tama-shi 206-8515, Japan
}

(Received 13 March 2006; and accepted 5 April 2006)

\begin{abstract}
The majority of research for the calcitonin gene-related peptide (CGRP) in the stomach has been devoted to the submucosal blood flow, and only slight attention has been paid to its involvement in the gastric epithelial function. In this study, we examined the age-related change in the CGRPcontaining nerves and its effects on the mucus metabolism. We compared the immunoreactivity for CGRP in the gastric mucosa of 7-week-old rats (young) to that of 52-week-old animals (middle-aged). The effects of CGRP on the mucin biosynthesis were compared using the stomachs from both young and middle-aged rats. The nitric oxide synthase (NOS) activity was measured in the surface and deep mucosa of the gastric corpus. The density of the CGRP nerve fibers was reduced in both the lamina propria and submucosa of the middle-aged rats compared to the young rats. CGRP stimulated the mucin biosynthesis in the cultured corpus mucosa from the 7-week-old rats, but not from the 52-week-old rats. The total NOS activity of the surface layer in the corpus mucosa was markedly reduced in the middle-aged rats compared to the young rats. These findings demonstrate the age-dependent reduction in the CGRP-induced mucin biosynthesis, as well as in the density of the CGRP fibers in the rat stomach. The decreased NOS activity in the surface layer of the oxyntic mucosa in the aged rats may also be a principal cause for the lack of regulation of the mucin biosynthesis by CGRP.
\end{abstract}

Aging is associated with an increased incidence of gastroduodenal mucosal injury in humans $(2,23)$, but little information is available about the mechanisms responsible for this phenomenon in the gastric mucosa. Several studies have shown age-related derangements in various functions of the gastrointestinal tract, such as a decrease in the gastric mucosal blood flow, and an increase in mucosal sus-

Address correspondence to: Dr. Takafumi Ichikawa, Department of Biochemistry, Kitasato University School of Medicine 1-15-1 Kitasato, Sagamihara, Kanagawa 228-8555, Japan

Tel: +81-42-778-9267, Fax: +81-42-778-8441

E-mail: t.ichika@kitasato-u.ac.jp ceptibility to acid injury $(10,29)$. Knowledge regarding which step in the regulatory mechanism is most associated with the progressive decline in these gastric functions is, indeed, very important in the clinical gastroenterology of aging.

The calcitonin gene-related peptide (CGRP), recognized as a neurotransmitter of afferent nerve fibers within the gastric mucosa, has been reported by several laboratories $(13,25)$ to counteract mucosal damage caused by ethanol and other injury-related factors. The underlying mechanism could be the CGRP-induced increase in the gastric submucosal blood flow. Gronbech and Lacy (10) indicated that the impaired mucosal defense and reduced restitution in the stomach of aged rats contributed to the 
decreased density of the CGRP-containing nerve fibers distributed in the submucosa. Although CGRPimmunoreactive nerve fibers mainly innervate the submucosal microvasculature $(9,32,35)$, a certain part of these fibers is shown to run parallel and close to the gastric glands in the lamina propria, some of which approach the mucus-secreting surface epithelial cells of the rat stomach $(7,37)$. Compared with the submucosal area, little attention has been paid to the CGRP effector in the other region of the gastric mucosa, particularly the surface epithelium.

Previously, we found that exogenous CGRP acts on the surface epithelial cells of the rat gastric corpus without vascular functions (15). These cells produce a gel-forming, high molecular weight mucus glycoprotein (mucin), an important mucosal defensive factor (1). Because the suggestion that gastric mucosal protection elicited by CGRP $(5,28)$ is due not only to a hyperemia-dependent mechanism (14), but also to the hyperemia-independent activation of the mucus cell function, interest has focused on the age-related change in the distribution and effect of CGRP on the surface layer of the gastric mucosa.

In the first step of this study, we sought to determine whether or not the immunoreactivity of CGRP in the gastric mucosal layers of middle-aged rats were different from that of young rats. In the second part, the effects of the exogenous CGRP on the mucin biosynthesis were compared using the stomachs of young and middle-aged rats. Furthermore, we examined the nitric oxide synthase (NOS) activity in the gastric mucosa of the young and middleaged rats since the CGRP-induced stimulation of the mucin biosynthesis is mediated by NOS (15).

\section{MATERIALS AND METHODS}

Experimental animals. Male Wistar rats (young: 7-weeks old; middle-aged: 52-weeks old) were obtained from SLC (Shizuoka, Japan). All rats were fasted for $24 \mathrm{~h}$ before the experiments and had free access to water during this time.

Drugs and chemicals. The following substances were used in this study: rabbit polyclonal antibody against CGRP (Cambridge Research Biochemicals, Northwich, UK); rabbit polyclonal antibody for protein gene product 9.5 (PGP 9.5) (UltraClone, Ltd., Isle Of Wight, UK); rat $\alpha$-CGRP (Peptide Institute, Osaka, Japan); D-[1,6- $\left.{ }^{3} \mathrm{H}(\mathrm{N})\right]$ glucosamine hydrochloride $(1787 \mathrm{GBq} / \mathrm{mmol}$, New England Nuclear, Boston, USA); L-[2,3,4,5- $\left.{ }^{3} \mathrm{H}\right]$ arginine monohydrochloride
(2.63 TBq/mmol, Amersham Pharmacia Biotech, Bucks, UK). The rat $\alpha$-CGRP was dissolved in phosphate-buffered saline (PBS). Stock solutions of this drug were freshly prepared, and the reported concentrations are the final bath concentrations.

Immunohistochemical staining. The animals were anesthetized, then intracardially perfused with heparinized saline followed by a fixative solution $(4 \%$ paraformaldehyde and $0.2 \%$ picric acid in $0.1 \mathrm{M}$ PBS, pH 7.4). The stomachs were excised from the body, and the corpus mucosa was selected and immersed in the same fixative for an additional $6 \mathrm{~h}$ at $4^{\circ} \mathrm{C}$. After a brief wash, the specimens were transferred to $30 \%$ sucrose and kept overnight at $4^{\circ} \mathrm{C}$. The specimens were then cut into $10 \mu \mathrm{m}$ sections using a cryostat and mounted on poly-L-lysine-coated slides. The sections were immunohistochemically stained with CGRP antiserum using the peroxidaseantiperoxidase (PAP) method. The immunostaining process was detailed in a previous report (24). The rabbit polyclonal antiserum directed against CGRP was diluted to $1: 1,500$. Adjacent sections were incubated with the polyclonal antibody for PGP 9.5 (diluted $1: 2,000)$ to identify the total population of the nerve fibers. To demonstrate the existence of CGRP and PGP 9.5, the section was then incubated with goat anti-rabbit IgG (diluted $1: 200$, Cappel, Durham, USA). After washing, the section was overlaid with the rabbit PAP complex (diluted $1: 200$, Jackson, West Grove, USA).

Tissue culture and measurement of synthesized mucin. Immediately after the rats were euthanized with $\mathrm{CO}_{2}$, their stomachs were excised and cut along the greater curvature. The glandular part was selected, separated into the corpus and antrum, and cut into small $2 \times 2 \mathrm{~mm}$ sections. Eight fragments were treated with $0.75 \mathrm{~mL}$ of culture medium and $0.05 \mathrm{~mL}$ of the test substances. The medium consisted of 90\% Eagle's minimum essential medium and 10\% dialyzed fetal calf serum with $370 \mathrm{kBq} / \mathrm{mL}$ of $\left[{ }^{3} \mathrm{H}\right]$ glucosamine hydrochloride. The tissue fragments were maintained at $37^{\circ} \mathrm{C}$ for $5 \mathrm{~h}$ in $5 \% \mathrm{CO}_{2}$ and $95 \%$ air. Upon completion of the culture period, the tissues were homogenized in Tris- $\mathrm{HCl}$ buffer containing Triton X-100. The extraction and isolation of the mucin were performed as previously described (18). The homogenate was centrifuged and the obtained supernatant was applied onto a Bio-Gel A-1.5 m column $(1 \times 30 \mathrm{~cm})$. Each of the $0.8 \mathrm{~mL}$ fractions were collected and the radioactivity was measured by a scintillation counter (Beckman, Mod- 
el LS-2800, USA) using Aquasol-2 (New England Nuclear) as the scintillant. To compare the synthetic activity of the mucin, the total radioactivity of this fraction was divided by the tissue protein content of each homogenate and expressed as dpm/mg of the tissue protein. Protein content in the tissue homogenate was determined using a Pierce protein assay kit with bovine serum albumin as the standard.

Cesium chloride ( $\mathrm{Cs} C \mathrm{Cl}$ ) equilibrium gradient centrifugation. For further characterization and purification of the radioactive substances obtained as mucin, fractions corresponding to the void volume of the Bio-Gel column were collected and used for the $\mathrm{CsCl}$ equilibrium density gradient centrifugation. The starting density was adjusted to $1.40 \mathrm{~g} / \mathrm{mL}$ by the addition of $\mathrm{CsCl}$ dissolved in $3 \mathrm{M}$ guanidine$\mathrm{HCl}$. After centrifugation at $150,000 \times \mathrm{g}$ for $120 \mathrm{~h}$ at $10^{\circ} \mathrm{C}$ (Hitachi 65P, RPS-40T rotor), each gradient was separated into a $0.5 \mathrm{~mL}$ fraction, its radioactivity was measured and its density was determined by weighing a definite volume of the corresponding fraction.

Assay of NOS activity. After selecting the corpus from the 7- and 52-week-old rat stomachs, the surface mucosa was quickly removed from the remaining deep mucosa according to our previously described method (15). This surface layer has been shown to consist largely of the surface mucus cells stained with the galactose oxidase-cold thionine Schiff (GOTS) method (22). The NOS activity was measured by the modified method of Bredt and Snyder (3) using an NOS assay kit (Calbiochem, San Diego, USA). Briefly, the surface or deep layers of the corpus tissues were weighed, and then homogenized at $4^{\circ} \mathrm{C}$ in 20 volumes (relative to the sample weight) of buffer containing $1 \mathrm{mM}$ EDTA, $1 \mathrm{mM}$ EGTA, and $25 \mathrm{mM}$ Tris-HCl, $\mathrm{pH}$ 7.4. The homogenates were centrifuged and the obtained supernatants were used for the NOS assay. Each sample $(10 \mu \mathrm{L})$ was added to $0.1 \mu \mathrm{M}$ calmodulin, $0.75 \mathrm{mM} \mathrm{CaCl}_{2}$, $1.25 \mathrm{mM}$ NADPH, $3.75 \mu \mathrm{M}$ tetrahydrobiopterin, $1.25 \mu \mathrm{M}$ flavin adenine dinucleotide, $1.25 \mu \mathrm{M}$ flavin mononucleotide, $0.45 \mu \mathrm{M} \mathrm{L}-\left[{ }^{3} \mathrm{H}\right]$ arginine and $25 \mathrm{mM}$ Tris-HCl, pH 7.4 (total volume: $50 \mu \mathrm{L}$ ) and incubated for $30 \mathrm{~min}$ at $37^{\circ} \mathrm{C}$. After incubation, the reactions were stopped with a buffer containing EDTA. The NOS activity in these supernatants was measured by monitoring the biochemical conversion of $\mathrm{L}-\left[{ }^{3} \mathrm{H}\right]$ arginine to $\mathrm{L}-\left[{ }^{3} \mathrm{H}\right]$ citrulline using the sodium form of a cation exchange resin column which absorbs L- $\left[{ }^{3} \mathrm{H}\right]$ arginine. L- $\left[{ }^{3} \mathrm{H}\right]$ Citrulline was eluted and its radioactivity was measured to determine the NOS activity.

Statistical analysis. The values presented in the Table 2 are given as means \pm S.D. A one-way analysis of variance (ANOVA) with Dunnett's test was used for the statistical analysis with $\mathrm{P}<0.05$ being taken as significant. The NOS activity in Fig. 4 is expressed as $\mathrm{pmol} / \mathrm{min} / \mathrm{g}$ tissue protein and represent means \pm S.D. The differences in the mean values between the 7- and 52-week-old rat groups were analyzed by the Student's $t$-test.

\section{RESULTS}

Immunohistochemical staining with CGRP antiserum in gastric mucosa of young and middle-aged rats

Fig. 1 shows microphotographs of frozen sections from the corpus of young and middle-aged rats stained with CGRP antiserum. The CGRP immunoreactivity was readily detected in the nerve fibers located in the lamina propria and submucosal layer. In the young rats, the density of the CGRP-immunoreactive fibers in both layers of the gastric mucosa was $50 \sim 60 \%$ of the total PGP 9.5-immunoreactive fibers (data not shown). Aged rats had markedly
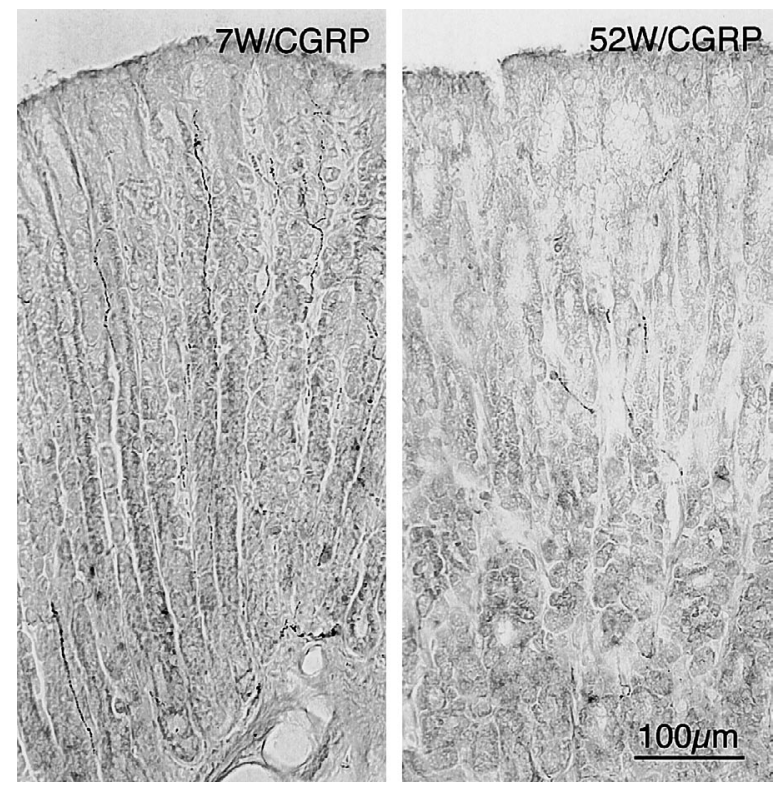

Fig. 1 Photomicrographs of rat corpus mucosa immunostained for CGRP. CGRP immunoreactivity was readily found in the lamina propria of the 7-week-old rat corpus mucosa (7W/CGRP). In contrast, the middle-aged rat had markedly fewer and sometimes no CGRP nerve fibers (52W/CGRP). Original magnification, $\times 60$. 
fewer and sometimes no CGRP-immunoreactive fibers in the gastric mucosa. The changes in the amount of the CGRP-immunoreactive nerve fibers in the young and middle-aged rat stomachs are summarized in Table 1. The density of the CGRP-containing nerve fibers was reduced in both the lamina propria and submucosa of the middle-aged rats compared to the young rats, although the amount of the total neuronal population stained for PGP 9.5, a pan-neuronal marker, was not significantly different with respect to age.

Extraction and purification of corpus mucin from young and middle-aged rat stomachs

Fig. 2 shows the elution profile of the Bio-Gel A-1.5 m chromatography of the radiolabeled extracts obtained from the corpus specimens of the 7- and 52 -week-old rat stomachs. The macromolecules of the middle-aged rat stomach were detected in the void volume of the column as well as those of the young ones (Fig. 2). $\left[{ }^{3} \mathrm{H}\right]$ Glucosamine incorporation into the gastric macromolecular fraction (Fr-1) was similar in the middle-aged and young rats. For further characterization of these radiolabeled macromolecules, the $\mathrm{CsCl}$ equilibrium density gradient centrifugation was carried out. Fig. 3 shows the distribution of the radioactivity of the high molecular glycoconjugates following the gradient centrifugation. Comparable profiles were obtained from the middle-aged and young rat samples. Both radioactive components displayed a sharp peak at a density of 1.35 to $1.45 \mathrm{~g} / \mathrm{mL}$.

\section{Influence of CGRP on gastric mucin biosynthesis in} the young and middle-aged rats

Table 2 shows the biosynthetic activity of the corpus mucin in the young and middle-aged rats as measured by $\left[{ }^{3} \mathrm{H}\right]$ glucosamine incorporation with or without CGRP. In the controls without the addition of the peptide, the mucin biosynthesis was virtually unchanged in the young and middle-aged rats. In the corpus mucosa of the young rats, the addition of CGRP significantly enhanced the $\left[{ }^{3} \mathrm{H}\right]$ glucosamine incorporation into the mucin in a concentration-dependent manner. In contrast to the results for the young rats, in the middle-aged rats, there was no significant change in the mucin biosynthesis in the corpus mucosa after the addition of CGRP (Table 2).

In the antrum of both the 7- and 52-week-old rats, no significant change could be detected in the mucin biosynthesis after the addition of CGRP (data not shown).

NOS activity in corpus tissue from young and middle-aged rats

Fig. 4 shows the change in the total NOS activity of the surface and deep layers of the corpus mucosa with age, as determined by measuring the conversion of $\mathrm{L}-\left[{ }^{3} \mathrm{H}\right]$ arginine to $\mathrm{L}-\left[{ }^{3} \mathrm{H}\right]$ citrulline. The total NOS activity of the surface layer was more clearly reduced in the middle-aged rats than in the young rats, although that of the deep mucosa was similar in both the middle-aged and young animals.

\section{DISCUSSION}

Considerable evidence $(6,7,21,36)$ indicates that nerve fibers immunoreactive for neuropeptides including CGRP distribute in the lamina propria and submucosal layer of the mammalian gastric mucosa, although their densities were different among the neuropeptides. In the lamina propria and submucosa of the young rat stomach, the density of the CGRPcontaining fibers was reported to be $58.7 \pm 11.3 \%$ and $50.3 \pm 9.6 \%$, respectively, as quantified by the percentage of each total neuronal population stained for PGP 9.5 (7). A previous study showed a lower density for the CGRP-positive nerve fibers around

Table 1 Density of CGRP containing nerve fibers in the corpus and antrum of young and middle-aged rat stomachs

\begin{tabular}{lcccc}
\hline & \multicolumn{2}{c}{ PGP 9.5 } & \multicolumn{2}{c}{ CGRP } \\
\cline { 2 - 5 } & 7-week-old rats & 52-week-old rats & 7-week-old rats & 52-week-old rats \\
\hline Corpus & & & & \\
$\quad$ Lamina propria & ++++ & $++\sim+++$ & +++ & + \\
Submucosal layer & +++ & $++\sim+++$ & ++ & + \\
Antrum & & & +++ & + \\
Lamina propria & +++ & $++\sim++$ & ++ & + \\
Submucosal layer & ++ & ++ & + & + \\
\hline
\end{tabular}

Grading of frequency of immunoreactive nerve fibers: \pm very few, + few, ++ moderate number, +++ many, ++++ abundant 


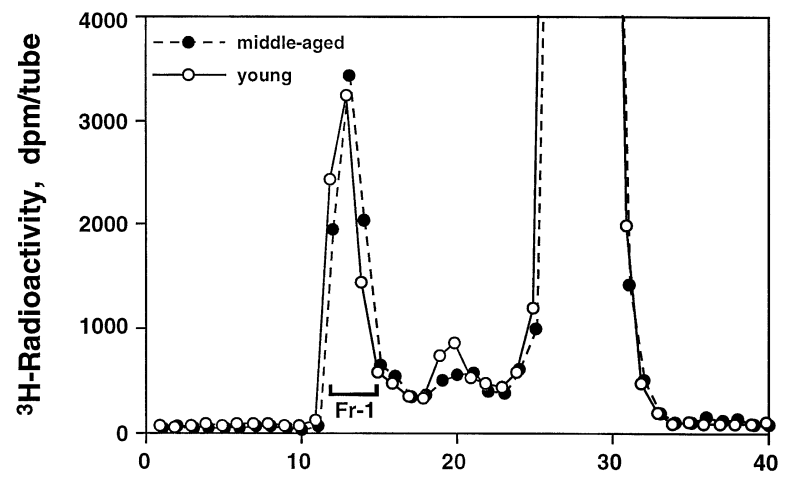

Fraction Number, $0.8 \mathrm{ml} /$ tube

Fig. 2 Elution profiles of ${ }^{3} \mathrm{H}$-labeled extracts from corpus mucosa during Bio-Gel A-1.5m column chromatography. Tissue fragments obtained from the 7- and 52-week-old rats were cultured for $5 \mathrm{~h}$ at $37^{\circ} \mathrm{C}$ in the presence of $\left[{ }^{3} \mathrm{H}\right]$ glucosamine hydrochloride. The ${ }^{3} \mathrm{H}$-labeled molecules were extracted from the tissues and then applied to a column $(1 \times 30 \mathrm{~cm})$ of Bio-Gel A-1.5m previously equilibrated with the Tris buffer containing $2 \%$ Triton $\mathrm{X}-100$.

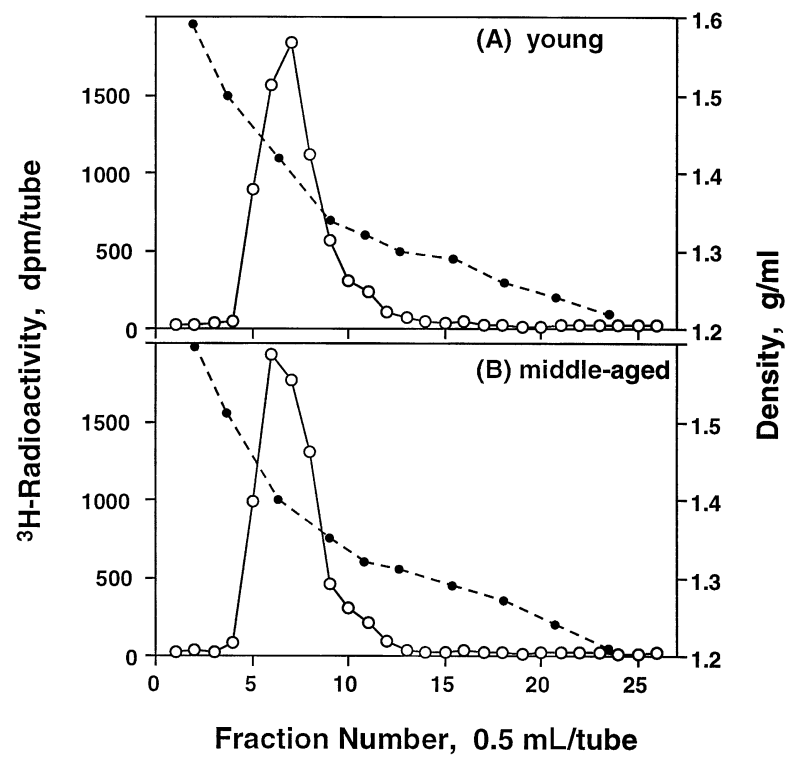

Fig. $3 \mathrm{CsCl}$ equilibrium centrifugation of ${ }^{3} \mathrm{H}$-labeled macromolecules. ${ }^{3} \mathrm{H}$-labeled macromolecules ( $\mathrm{Fr}-1$ in Fig. 2) were obtained as the excluded fraction from a Bio-Gel A-1.5m column and then centrifuged. Centrifugation was performed at $150,000 \times g$ for $120 \mathrm{~h}$ at $10^{\circ} \mathrm{C}$ with a starting density of $1.40 \mathrm{~g} / \mathrm{mL}$. Each fraction was assayed for density (closed circles) and radioactivity (open circles). (A) young rat stomach, (B) middle-aged rat stomach.

the submucosal blood vessels in the stomach of the aged rats compared to the young rats (10), resulting in a potentially less protective activity of the gastric mucosa in aged animals than that in the young ones.
Our data demonstrate that, as compared to the young rats, middle-aged rats have markedly fewer CGRP nerve fibers in the lamina propria, as well as in the submucosal layer of the gastric mucosa. Morphological studies indicate that the gastric mucosa of aged rats show definite histologic and ultrastructural changes even under normal conditions (12). In 95 -week-old rats, erosions are apparent over $80 \%$ of the gastric mucosa after starvation for 24 hours (11). In contrast, no significant gastric mucosal damage can be detected in the gastric mucosa of a 7-weekold rat after 24 hours of fasting. Previously, we found that CGRP exerts stimulatory effects on the mucin biosynthesis in the surface epithelial cells of the gastric corpus mucosa from the 7-week-old rats (15). Because stimulation of the corpus mucin synthesis is closely related to the mucosal protective activity (19), these finding suggest that the decrease in the CGRP nerve fibers in the lamina propria, as well as the submucosa, could be a cause of the impaired mucosal defense mechanism in the aged rats.

The results of the present study show that the elution pattern of the $\left[{ }^{3} \mathrm{H}\right]$ glucosamine-labeled extracts from the corpus mucosa of the 52-week-old rats was similar to that from the young rats based on Bio-Gel A-1.5 m column chromatography. Moreover, the high molecular weight $\left[{ }^{3} \mathrm{H}\right]$ glucosamine-labeled substance from the middle-aged rats formed a single peak by equilibrium centrifugation in a $\mathrm{CsCl}$ density gradient at the typical density of the purified mucins (4), as well as that from young rats. In the 7-weekold rat stomachs, we have already demonstrated that most of the radiolabeled oligosaccharides obtained from the high molecular weight glycoconjugates are distributed within the molecular size corresponding to the oligosaccharides obtained from the purified rat gastric mucin (18). Moreover, treatment with either hyaluronidase or amylase did not change the profile of the radiolabeled oligosaccharides in a TSK gel HW-50S chromatogram, indicating the negligible contamination of polysaccharides, such as hyaluronic acid, chondroitin sulfate and glycogen. Goso and Hotta (8) reported that the $\left[{ }^{35} \mathrm{~S}\right]$ sulfate-labeled mucin prepared by a procedure similar to that used in this study did not contain sulfated proteoglycans, such as chondroitin sulfate, heparin, or keratan sulfate. These observations demonstrate that most of the $\left[{ }^{3} \mathrm{H}\right]$ glucosamine-labeled substances obtained from the void volume peak during the Bio-Gel A-1.5 m gel-filtration column chromatography are mucin-type glycoproteins (34), and the radioactivity measurement of this peak is thought to be valid for estimation of the biosynthetic activity of the gastric 
Table 2 Effects of CGRP on $\left[{ }^{3} \mathrm{H}\right]$ glucosamine incorporation into mucin in corpus tissue of young and middle-aged rat stomachs

\begin{tabular}{clccc}
\hline & \multicolumn{2}{c}{ 7-week-old rats } & \multicolumn{2}{c}{ 52-week-old rats } \\
\cline { 2 - 4 } & \multicolumn{2}{c}{$\left[\begin{array}{c}\left.{ }^{3} \mathrm{H}\right] \text { glucosamine uptake } \\
\text { dpm } / \mathrm{mg} \text { tissue protein }(\% \text { of control) }\end{array}\right.$} & $\begin{array}{c}\left.{ }^{3} \mathrm{H}\right] \text { glucosamine uptake } \\
\mathrm{dpm} / \mathrm{mg} \text { tissue protein }(\% \text { of control })\end{array}$ \\
\hline $0 \mathrm{M}$ & $12427 \pm 2361$ & $(100 \pm 19)$ & $13463 \pm 2118$ & $(100 \pm 16)$ \\
$10^{-8} \mathrm{M}$ & $15161 \pm 746$ & $(122 \pm 6)$ & \multicolumn{2}{c}{ Not Determined } \\
$10^{-7} \mathrm{M}$ & $16404 \pm 870^{* *}$ & $\left(132 \pm 7^{* *}\right)$ & $12522 \pm 539$ & $(93 \pm 4)$ \\
$10^{-6} \mathrm{M}$ & $16901 \pm 1243$ & $\left(136 \pm 10^{* *}\right)$ & $12386 \pm 1212$ & $(92 \pm 9)$ \\
\hline
\end{tabular}

Values are expressed as means \pm S.D. from 5 different samples derived from 5 different rats. $* * \mathrm{P}<0.01$ as compared with the control value $(0 \mathrm{M})$.

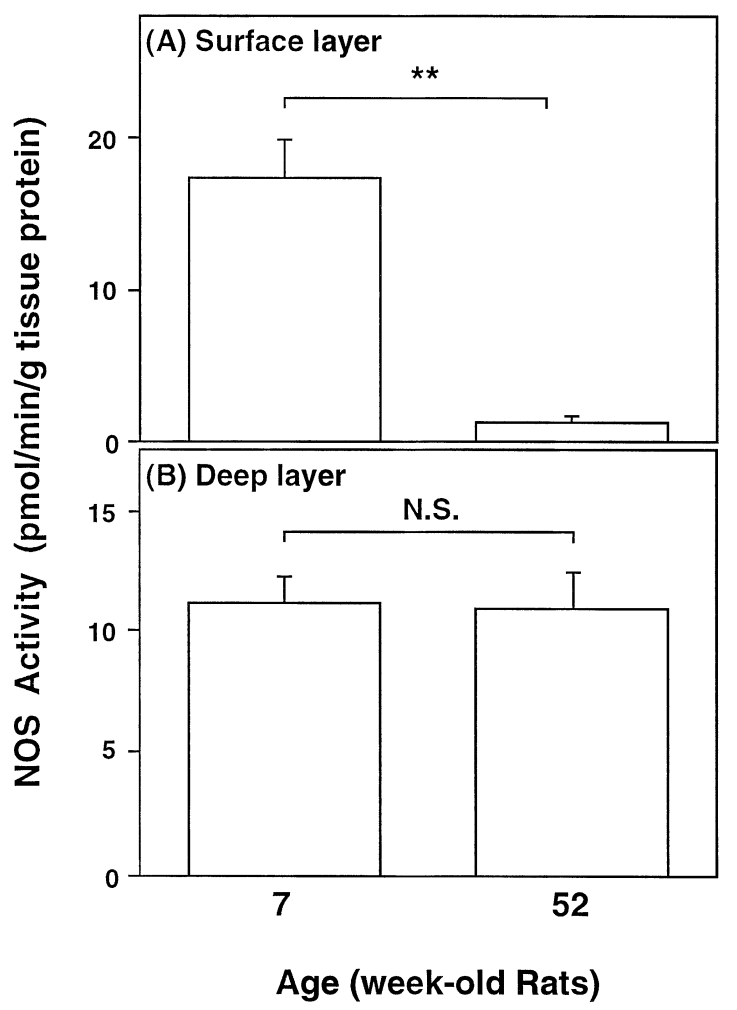

Fig. 4 Effect of age on the total NOS activity in the surface $(A)$ and deep layer $(B)$ of the rat corpus mucosa. The surface layer of the corpus mucosa was scraped off with forceps from the remaining deep mucosa based on our previously described method (12). These tissues were weighed, homogenized, and centrifuged. The obtained supernatants were incubated for $30 \mathrm{~min}$ at $37^{\circ} \mathrm{C}$ in the presence of $L-\left[{ }^{3} \mathrm{H}\right]$ arginine. The total NOS activity was measured by monitoring the biochemical conversion of L- $\left[{ }^{3} \mathrm{H}\right]$ arginine to $L-\left[{ }^{3} \mathrm{H}\right]$ citrulline. The values are expressed as $\mathrm{pmol} / \mathrm{min} / \mathrm{g}$ tissue protein and represent means \pm S.D. for different samples derived from 4 different rats. The asterisk indicates the statistical significance $\left({ }^{\star \star} P<0.01\right)$. N.S.: not significant.

mucin in the middle-aged rat as well as the young ones. Using this method, we examined the radioactivity distribution of the $\left[{ }^{3} \mathrm{H}\right]$ glucosamine-labeled mucin in the tissue and that excreted into the medium. Of the total ${ }^{3} \mathrm{H}$ radioactivity incorporated into the mucin, $10 \sim 15 \%$ was found in the medium, and this amount was independent of the drug addition (18), indicating that most of the secreted mucins were retained in the adherent mucus gel attached to the surface epithelium in our experimental model.

The most notable finding in this study was that the effects of CGRP on the corpus mucin biosynthesis in young adult rats were distinct from those on the mucin biosynthesis in middle-aged rats. In the young rats, CGRP exerted stimulatory effects on the mucin biosynthesis in the oxyntic region at concentrations of $10^{-7} \sim 10^{-5} \mathrm{M}$. In contrast, this peptide had no significant effect on the mucin biosynthesis in the oxyntic mucosa from the middle-aged rats, although the mean biosynthetic activity was not significantly different in the young and middle-aged rats in the control situation. These results indicate that aging affects not only the density of the CGRP nerve fibers in the lamina propria, but also the responses of the gastric epithelium to CGRP.

Previously, CGRP-induced activation of the mucin biosynthesis in the stomachs of rats was shown to be completely blocked by both $N^{\mathrm{G}}$-nitroL-arginine, the NOS inhibitor, and the 2-(4carboxyphenyl)-4,4,5,5-tetramethylimidazoline-1oxyl-3-oxide sodium salt (carboxy-PTIO), a nitric oxide (NO) antidote that can react only with $\mathrm{NO}$, indicating that $\mathrm{NO}$ plays an important role in mediating the activation of the gastric mucin synthesis elicited by CGRP (15). In our previous study, the stimulant response of the gastric mucosa to isosorbide dinitrate, an exogenous NO-donor, was essentially the same in the young and middle-aged rats (16). Smits and Lefebvre (33) showed that the relaxant response to sodium nitroprusside, another exogenous NO-donor, in longitudinal muscle strips of the gastric fundus was not significantly different between the 3- and 12-month-old rats, but was signifi- 
cantly decreased in the 24-month-old rats. Taken together, these results suggest that the cyclic GMP pathway for NO is not affected by aging up to about 1 year.

Mollace et al. (30) reported the total NOS activity of the hippocampus to be lower in the aged rats than in the young rats, suggesting that this decrease could contribute to the age-related change in cerebral functions. Immunohistochemical observations have shown that NOS immunoreactivity existed in the surface epithelial cells, as well as in the nerve fibers distributed in the deep layer, of the young rat corpus mucosa (31). In the present study, the NOS activities in the distinct layers of the middle-aged rat gastric mucosa were compared with those of the young using a scraping method to separate the surface epithelial layer from the remaining deep mucosa of the stomach (15). The surface NOS activity of the 52-week-old rat stomach was significantly lower than that of the 7-week-old rat stomach, although the NOS activities in the deep mucosa were similar. Our results agree with those of a previous histochemical investigation (16), which found that the NOS immunoreactivity in the corpus mucosa of middle-aged rats was mainly detected in the deep layer and none was observed in the surface epithelial layer. These data indicate that the decreased NOS activity in the surface epithelial layer of the middle-aged rat corpus mucosa may be a principal cause for the lack of mucin biosynthesis regulation by CGRP.

We have already shown that CGRP stimulates the process of mucin production through specific receptors in the young rat stomach (15) in a manner similar to other actions, such as increased blood flow and inhibiting gastric acid secretion $(20,26,27)$. It is possible that the membrane changes, such as the functional importance of these receptors, partly participate in the age-related loss of the CGRP-induced stimulation of the mucin synthesis. The measurement of some variables in the surface epithelial cells, such as the receptor-population and receptorbinding activity, will help us to gain a better understanding of the results obtained in this study.

In this study, the antral tissue separated from the corpus was also cultured. In contrast, in the corpus mucosa, CGRP had no significant effect on the mucin biosynthesis in this region in the young and middle-aged rat stomachs. Although the distribution of the CGRP-immunoreactive nerve fibers in the antrum is very similar to that in the corpus, our data showed that the responsiveness of the gastric mucus cells to CGRP varies in the different regions of the stomach. Similarly, exogenous NO-donors significantly accelerated the mucin biosynthesis only in the oxyntic region but produced no significant change in the antral region of the rat stomach (17). These observations support the assumption that the mucin production is regulated in a different manner in the corpus and antrum of the gastric mucosa.

In summary, the present findings demonstrate the age-related change in the gastric mucin biosynthesis regulated by CGRP, as well as in the density of the CGRP nerve fibers distributed in the lamina propria of the rat stomach. Moreover, the decreased NOS activity in the surface layer of the oxyntic mucosa in the aged rats may be a principal cause for the lack of mucin biosynthesis regulation by the CGRP.

\section{Acknowledgments}

Part of this work was supported by Grants-in-Aid for Scientific Research from the Japanese Ministry of Education, Science, and Culture; and by the Integrative Research Program of the Graduate School of Medical Sciences, Kitasato University.

\section{REFERENCES}

1. Bansil R, Stanley E, Tsukahara M and LaMont JF (1995) Mucin biophysics. Annu Rev Physiol 57, 635-657.

2. Bonnevie O (1975) The incidence of gastric ulcer in Copenhagen county. Scand J Gastroenterol 10, 231-239.

3. Bredt DS and Snyder SH (1989) Nitric oxide mediates glutamate-linked enhancement of cGMP levels in the cerebellum. Proc Natl Acad Sci USA 86, 9030-9033.

4. Davies JR and Carlstedt I (2000) Isolation of large gel-forming mucins. In: Glycoprotein Methods and Protocols. The Mucins. Part I. Purification of Mucin (Corfield AP, ed.), pp 3-13, Humana Press Inc, New Jersey.

5. Doi K, Nagao T, Kawakubo K, Ibayashi S, Aoyagi K, Yano Y, Yamamoto C, Kanamoto K, Iida M, Sadoshima S and Fujishima M (1998) Calcitonin gene-related peptide affords gastric mucosal protection by activating potassium channel in Wistar rat. Gastroenterology 114, 71-76.

6. Ekblad E, Ekelund M, Graffner H, Håkanson R and Sundler F (1985) Peptide-containing nerve fibers in the stomach wall of rat and mouse. Gastroenterology 89, 73-85.

7. Gono Y, Ichikawa T, Hotta K, Takenaka T, Sakai F and Kusakabe T (1998) Topographical distribution of neuropeptidecontaining nerve fibers in the rat stomach: a quantitative analysis using antibodies against protein gene product 9.5 and gastric mucins. Biomed Res 19, 357-368.

8. Goso Y and Hotta K (1989) Types of oligosaccharide sulphation, depending on mucus glycoprotein source, corpus or antral, in rat stomach. Biochem $J$ 264, 805-812.

9. Green T and Dockray GJ (1988) Characterization of the peptidergic afferent innervation of the stomach in the rat, mouse and guinea-pig. Neuroscience 25, 181-192.

10. Gronbech JE and Lacy ER (1995) Role of gastric blood flow in impaired defense and repair of aged rat stomachs. Am J Physiol 269, G737-G744. 
11. Hinsull SM (1991) Effect of colloidal bismuth subcitrate on age related gastric lesions in the rat. Gut 323, 55-360.

12. Hollander D, Tarnawski A, Stachura J and Gergely H (1989) Morphologic changes in gastric mucosa of aging rats. Dig Dis Sci 34, 1692-1700.

13. Holzer P (1998) Neural emergency system in the stomach. Gastroenterology 114, 823-839.

14. Holzer P, Livingston EH, Saria A and Guth PH (1991) Sensory neurons mediate protective vasodilatation in rat gastric mucosa. Am J Physiol 260, G363-G370.

15. Ichikawa $\mathrm{T}$, Ishihara $\mathrm{K}$, Kusakabe $\mathrm{T}$, Hiruma $\mathrm{H}$, Kawakami $\mathrm{T}$ and Hotta K (2000) CGRP modulates mucin synthesis in surface mucus cells of rat gastric oxyntic mucosa. Am J Physiol 279, G82-G89.

16. Ichikawa $\mathrm{T}$, Ishihara $\mathrm{K}$, Kusakabe $\mathrm{T}$, Kawakami $\mathrm{T}$ and Hotta K (1999) Age-related stimulation by tetragastrin of gastric mucin biosynthesis in rat. Eur J Pharmacol 366, 87-92.

17. Ichikawa T, Ishihara K, Kusakabe T, Kawakami T and Hotta K (1999) Stimulant effect of nitric oxide generator and roxatidine on mucin biosynthesis of rat gastric oxyntic mucosa. Life Sci 65, PL41-46.

18. Ichikawa T, Ishihara K, Saigenji K and Hotta K (1993) Stimulation of mucus glycoprotein biosynthesis in rat gastric mucosa by gastrin. Biochem Pharmacol 46, 1551-1557.

19. Ichikawa T, Ishihara K, Saigenji K and Hotta K (1994) Effects of acid-inhibitory antiulcer drugs on mucin biosynthesis in the rat stomach. Eur J Pharmacol 251, 107-111.

20. Kato K, Martinez V, St Pierre S and Tache Y (1995) CGRP antagonists enhance gastric acid secretion in 2-h pylorus-ligated rats. Peptides 16, 1257-1262.

21. Keast JR, Furness JB and Costa M (1985) Distribution of certain peptide-containing nerve fibers and endocrine cells in the gastrointestinal mucosa in five mammalian species. $J$ Comp Neurol 236, 403-422.

22. Komuro Y, Ishihara K, Ishii K, Ota H, Katsuyama T, Saigenji K and Hotta K (1992) A separating method for quantifying mucus glycoprotein localized in the different layer of rat gastric mucosa. Gastroenterol Jpn 27, 466-472.

23. Krasinski SD, Russel RM, Samloff IM, Jacob RA, Dallal GE, McGandy RB and Hartz SC (1986) Fundic atrophic gastritis in an elderly population. $J$ Am Geriatr Soc 34, 800806.

24. Kusakabe T, Anglade P and Tsuji S (1991) Localization of substance P, CGRP, VIP, neuropeptide Y, and somatostatin immunoreactive nerve fibers in the carotid labyrinths of some amphibian species. Histochemistry 96, 255-260.

25. Lambrecht N, Burchert M, Respondek M, Muller KM and Peskar BM (1993) Role of calcitonin gene-related peptide and nitric oxide in the gastroprotective effect of capsaicin in the rat. Gastroenterology 104, 1371-1380.

26. Lawson DC, Mantyh CR and Pappas TN (1994) Effect of CGRP antagonist, alpha-CGRP $8-37$, on acid secretion in the dog. Dig Dis Sci 39, 1405-1408.

27. Li DS, Raybould HE, Quintero E and Guth PH (1991) Role of calcitonin gene-related peptide in gastric hyperemic response to intragastric capsaicin. Am J Physiol 261, G657G661.

28. Merchant NB, Goodman J, Dempsey DT, Milner RE and Ritchie WP (1995) The role of calcitonin gene-related peptide and nitric oxide in gastric mucosal hyperemia and protection. J Surg Res 58, 344-350.

29. Miyake H, Inaba N, Kato S and Takeuchi K (1996) Increased susceptibility of rat gastric mucosa to ulcerogenic stimulation with aging. Dig Dis Sci 41, 339-345.

30. Mollace V, Rodino P, Massoud R, Rotiroti D and Nistico G (1995) Age-dependent changes of NO synthase activity in the rat brain. Biochem Biophys Res Commun 215, 822-827.

31. Price KJ, Hanson PJ and Whittle BJR (1996) Localization of constitutive isoforms of nitric oxide synthase in the gastric glandular mucosa of the rat. Cell Tissue Res 285, 157-163.

32. Sharkey KA, Williams RG and Dockray GJ (1984) Sensory substance P innervation of the stomach and pancreas. Demonstration of capsaicin-sensitive sensory neurons in the rat by combined immunohistochemistry and retrograde tracing. Gastroenterology 87, 914-924.

33. Smits GJM and Lefebve RA (1995) Influence of age on the signal transduction pathway of non-adrenergic non-cholinergic neurotransmitters in the rat gastric fundus. $B r J$ Pharmacol 114, 640-647.

34. Spee-Brand R, Strous GJAM and Kramer MF (1980) Isolation and partial characterization of rat gastric mucus glycoprotein. Biochem Biophys Acta 621, 104-116.

35. Sternini C, Reeve JR and Jr Breeha N (1987) Distribution and characterization of calcitonin gene-related peptide immunoreactivity in the digestive system of normal and capsaicintreated rats. Gastroenterology 93, 852-862.

36. Sundler F, Brondin E, Ekelund E, Håkanson R and Uddmann R (1985) Sensory nerve fibers: Distribution of substance P, neurokinin A and calcitonin gene-related peptide. In: Tachykinin Antagonists (Håkanson R, Sundler F, eds.), pp3-14, Elsevier, Amsterdam.

37. Suzuki T, Kagoshima M, Shibata M, Inaba N, Onodera S, Yamaura T and Shimada H (1997) Effects of several denervation procedures on distribution of calcitonin gene-related peptide and substance P immunoreactive in rat stomach. Dig Dis Sci 42, 1242-1254. 